Review

\title{
Egg Consumption among Young People: A Study through the Application of the Logistic Regression Model
}

\author{
Carlo Giannetto, Angela Alibrandi, Agata Zirilli and Maurizio Lanfranchi
}

Department of Economics, University of Messina, Messina, Italy

\section{Article history}

Received: 25-01-2016

Revised: $12-06-2016$

Accepted: 24-06-2016

Corresponding Author:

Maurizio Lanfranchi

Department of Economics,

University of Messina,

Messina, Italy

Email: mlanfranchi@unime.it

\begin{abstract}
The purpose of the present survey is to study and to investigate the proper eating style, focusing the attention on the propensity to "egg" consumption, in the diet of young people, with reference to the students attending the University of Messina. The data collection technique that was used consisted of the administration of a distributed anonymous ad hoc questionnaire by directly interviewing a sample of university students. In order to individualize the possible variables which may influence the frequency of egg consumption, a logistic regression model was used. It is a particular case of generalized linear model whose link function is the log it function. It is frequently applied when the dependent variable y is, dichotomous. The research results indicate that the only two statistically significant variables are the eating style and the reading of the product label. Moreover, the Hosmer and Leme show test for model's adequacy guaranteed that the estimates provided by the model are not significantly different from the observations.
\end{abstract}

Keywords: Egg Consumption, Young People, Eating Style, Food Model, Generalized Linear Model, Goodness-of-Fit Test

\section{Introduction}

According to the World Health Organization (WHO), the eggs which are properly consumed can help improve health, with the contribution of high quality proteins and a wide range of mineral salts and vitamins. In Europe, several interventions have been carried out in order to promote and improve the consumer safety, the farming and processing of eggs and of the derivative products (Cembalo et al., 2015; Migliore et al., 2015a). These safety measures, together with a correct manipulation, make this food a natural ingredient that is also safe for consumption (Fearne and Lavelle, 2011; Migliore et al., 2015b). To date, therefore, the security risk due to eggs has been almost completely overcome. Therefore, the contribution to health improvement is important for all ages. According to the guidelines for a healthy diet drawn up by the WHO, it is possible to consume eggs $(60 \mathrm{~g})$ on average twice or 4 times a week (for a requirement of $2100 \mathrm{kcal}$ ). When calculating the weekly portions of eggs, the part of the egg which is used in food preparations (homemade egg pasta, sweets, biscuits, etc.) must be considered as well (Heuer et al., 2015; Memon et al., 2009; Maga, 1982).

In Italy, egg consumption is experiencing a significant growth phase. This tendency is favoured both by the innovations in farming supported by the major producers and by a marketing activity aimed at orientating communication towards consumer welfare and health (Andersen, 2011; Sumner et al., 2011; Lanfranchi et al., 2014a). The action of the leading industries was directed to the promotion of the freshness and food safety aspect which are today two essential elements for purchasing choices. The introduction of the marking for each single egg bearing the laying date, has reassured consumers and has strengthened the whole category (Kosa et al., 2015; Tonsor, 2011). The considerable development of this important economic sector is demonstrated by the evolution of the production from around 4 billion units of 1958 to the current 12,5 billion. About 2.500 people used to work in poultry holdings (Hayat et al., 2010). The severe economic crisis which has hit our Country has continued to favour the purchases of eggs, to the extent that the average per capita annual consumption in 2014 was of 218 units (around 13,77 kg), 142 of which are eaten "fresh" and the remaining ones as ingredients in other dishes. In the early $1950 \mathrm{~s}$ every Italian consumed on average around 120 eggs $(6,43 \mathrm{~kg})$ (Table 1). The increase in egg consumption is in line with the Engel's law and with the well-known Giffen's paradox (Pecorino et al., 2016; Tudisca et al., 2015; Migliore et al., 2015c). In fact, since households, especially those with lower income, could not avoid some necessary expenses, such as rent, medical expenses and transport, they were forced to remodel their food basket 
by mainly purchasing basic foodstuffs, such as pasta, eggs and bread (Caracciolo et al., 2015; Tudisca et al., 2014; Wilkins et al., 2000). This tendency has led to a contraction in the purchase of olive oil, drinks, beef, fresh fish and fresh milk (Winkler, 2015). In the world, the average per capita consumption in 2014 was of 139 eggs per year, 8 eggs per person $(-5,4 \%)$ less than 2013. The most egg consuming country is South Africa (153 eggs per person each year). The following figure shows the main countries of the world for average per capita egg consumption (Fig. 1).

Italy manages to almost entirely cover the need for eggs, which is equal to $94,8 \%$. The recent alignment of laying hens farms with the European legislation on laying hen welfare has influenced the production causing a contraction (Table 2). However, in order to satisfy the internal demand, it was necessary to resort to imports which, according to recent studies conducted by Istat, have decreased by $20 \%$ compared to 2013 (Katz et al., 2005; EUFIC, 2010). Considering the balance between import and export, 694 million eggs have been imported into the Italian territory. In terms of profitability, the framework is more complex. Prices have increased by $58,6 \%$ for eggs for consumption. In the same period, the production costs have gone up on average by about $13 \%$, owing to the increase in the prices of soybean ceral raw materials and of rearing costs (Schimmenti et al., 2013; Oliveira et al., 2013; Mesías et al., 2011).

\section{Research Objective}

The purpose of the present survey is to study and to investigate the proper eating style, with a particular focus on the propensity to "egg" consumption, in the diet of young people, with particular reference to the students who attend the University of Messina. We analized the answers provided by the interviewed students, with reference to some personal features, such as: Age, gender, number of members in the household, municipality of residence, year of the course, parents' studies and some other variables related life style: Smoke, alcohol consumption, sports activity and food style. The results produced by this survey can certainly be used for cognitive purposes and for future research, even though they cannot be considered as originating from a typical random sampling procedure. Indeed, it is a pilot survey on a large number of respondents in which information seems particularly important for the reduction of information asymmetry, a condition to which the consumer is subject at the time of purchase.

Table 1. Average per capita annual egg consumption in Italy from 1950 up today

\begin{tabular}{ll}
\hline Year & Per capita consumption $(\mathrm{kg})$ \\
\hline 1950 & 6,43 \\
1960 & 8,88 \\
1970 & 12,6 \\
1980 & 12,03 \\
1990 & 13,67 \\
2000 & 13,7 \\
2010 & 13,2 \\
2013 & 13,86 \\
2014 & 13,73 \\
\hline
\end{tabular}

Source: Unaitalia processing on Istat data 2015

Table 2. Italian balance of eggs for consumption (n. of item)

\begin{tabular}{llll}
\hline & 2013 & 2014 & differential 2013/2014 \\
\hline Production & 12.168 .000 .000 & 12.534 .000 .000 & $3 \%$ \\
Import & 1.766 .000 .000 & 1.398 .000 .000 & $-20,80 \%$ \\
Export & 439.000 .000 & 704.000 .000 & $60,40 \%$ \\
Balance shell eggs & 1.327 .000 .000 & 694.000 .000 & $-47,70 \%$ \\
Internal use & 13.495 .000 .000 & 13.228 .000 .000 & $-1,90 \%$ \\
Per capita consumption & 220 & 218 & $-1,40 \%$ \\
\hline
\end{tabular}

Source: Unaitalia processing on Istat data 2015

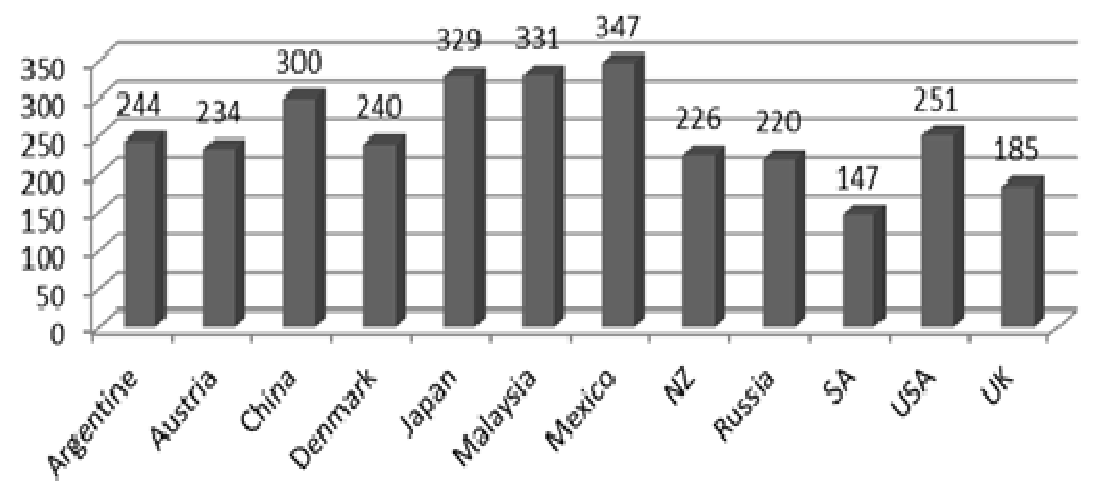

Fig. 1. Per capita egg consumption in the main countries of the world in 2014 


\section{Materials and Methods}

The data were collected by means of the administration of a distributed anonymous ad hocquestionnaire, directly interviewing a sample of university students (Lanfranchi et al., 2014b). The data collection was conducted in such a way as to respect the dislocation of university departments within the scientific community as much as possible. The surveys were conducted within the departments of the University of Messina during September and November 2015. The sample is formed by 305 students. Even if it does not represent a properly statistical sample, due to the lack of a database for the random extraction of the respondents' names, the obtained results can be regarded as indicative, considering not only the size of the sample but also the quality of the data. To identify the existence of any variables that may affect the frequency of egg consumption, a logistic regression model was used. It is a particular case of generalized linear model whose link function is the $\log$ it function. It is a regression model which is applied in those cases when the dependent variable $\mathrm{y}$ is, indeed, dichotomous, referable to a value of 0 and 1 . In recent years, several searches have been conducted and many theories have been formulated regarding the quality of eggs, farming methods and the benefits a man can receive by consuming this product. Most of these studies are also focused on the problems that this food can generate, such as that of salmonellas is (especially the type caused by enteric serotype Enteritidis Salmonella, for its peculiar capability of colonizing hens' ovarian tissue and of being present inside intact shell-eggs), risks of vascular diseases (Zazpe et al., 2011), or, on the basis of the latest events, that of dioxin, which is originated from the problem of avian flu (Winkler, 2015; Lanfranchi et al., 2014c). For example, a study by Maga (1982), focuses on the chemical composition of eggs and on the relationship among the variations in chemical composition. Maga (quoting a former study by Colas et al., 1979) states that changes in breeding and in the protein content of eggs may alter their quality, but not their flavour. In the literature it is pointed out that contamination may occur more easily in small rural farms that in the big industrial production. Therefore, according to these studies, the sources of supply of eggs for consumption play a fundamental role in determining the risks for the consumer. Despite the avaiability of a wide range of information on the nutritional aspects of eggs related to the outbreak of some diseases in humans (cardiovascular and tumorous diseases), detailed and updated information on the average consumption of eggs in Italy is not available. The available data on consumption are generally collected by using types of aggregation and units of measurement (expenditure on purchase) (Zazpe et al., 2011). The following are brief other international scientific studies relating to the benefits related to a proper consumption of eggs. An example is the study of Luc Djoussé and Gaziano (2008). Another study was carried out by Song and Kerver (2000). Another research is to Menonetal.

it was concluded that egg consumption
showed positive trend and most of consumers
preferred 1-3 commercial eggs daily
especially at breakfast as first preference to
eat omelet after cooked by their wives, but the
low purchase power resulted weaker
purchasing frequency. Egg consumption was
increased in winter as compared to summer,
in increasing egg prices and no considerable
effect of any disease outbreak was found.
Consumers sacrifice the eggs in serious
sickness for their early healthiness/remedy
from diseases. Consumers also showed
positive response in consuming eggs in
summer season as well.

Analysis of the Egg Consumption Preference among the Students of the University of Messina: Sample Selection and Characteristics

The actual sample (305 respondents) has been subdivided according to some socio-demographic segmentation variables: Gender, city of birth, age, qualification. The average age of the interviewed is about 23. The age group range from 19 and 47 (this latter data is attributable to those students who are behind in the course schedule and to those who are enrolled in another degree course). When analyzing the social and demographic features of the sample, we can note that the sample is composed by $35.4 \%$ males (108 units) and $64,6 \%$ women (197 units). The interviewed students are resident in Messina province $(25,3 \%)$, in other Sicilian municipalities $(18,8 \%)$ and in Calabria $(27,7 \%)$. The average number of the household members is 4 . With reference to the parental education, $52,8 \%$ of fathers and $54,6 \%$ of mothers have a degree, while $21,3 \%$ of fathers and $19,3 \%$ of mothers achieved a university degree. When we analyze the lifestyle of the students who attend the University of Messina, we can highlight that about $63 \%$ do not smoke and $45,7 \%$ do not consume alcohol. Besides, those who practise sporting activities once or twice a week represent $39,7 \%$ of the sample and $95,4 \%$ of young people do not exclude any food in their daily diet. Based on the responses obtained from the administered questionnaire, $71,5 \%$ of the respondents claim to attend a three-year university degree course, while $26,6 \%$ claim to attend a master degree course. The statistical analysis outlines a particular trasversality in the weekly consumption as regards gender, while in the other socio-demographic characteristics no relevant percentage differences were recorded. 


\section{Analysis for Measuring Egg Consumption Among University Students: The Food model}

About $65,5 \%$ of the interviewed students state that they consume eggs once or twice a week, $12 \%$ never eat them and only $3 \%$ consume them every day (Table 3 ). As regards the respondents' knowledge of the information provided by the label, the obtained data is substantially balanced. About $54 \%$ of the students declare that they can read the label, while $46 \%$ are not sufficiently informed. In order to verify the respondent's degree of information asymmetry concerning the methods of producing the product and its provenance, he was asked if he is aware of the difference between the production of biological eggs and that through industrial farming. In this case, the student seems to be more informed. Indeed, $75 \%$ of the respondents claim to know the difference. As regards the consumption patterns, the respondent was asked if he consumes eggs "alone" or with other ingredients (Table 4). As may be seen in Table 4, most of the respondents prefer to consume eggs as an ingredient of other dishes. As regards purchases, he was asked how much he is willing to spend in order to consume biological eggs (Table 5). Many respondents (32\%), being aware that the consumption of biological eggs represents an additional guarantee in terms of food safety, are willing to buy an egg even at a price higher than 50 euro cents.

\section{Analysis of the University Student's Egg Consumption in Relation to his Lifestyle}

A specific analysis of the lifestyle of the university students attending the University of Messina shows that more than $63 \%$ of the sampled respondents do not smoke, $45,7 \%$ do not take alcohol, $39,7 \%$ play sport once or twice a week and 95,4\% declare themselves omvivorous. On the basis of the data deriving from the descriptive analysis, $71,5 \%$ of the interviewed students is attending a three-year degree course, while $26,6 \%$ are enrolled in a master degree course (Lanfranchi et al., 2015). If we analyze the percentage profiles concerning to the gender, we can note that women habitually consume more eggs than men (Table 6). Considering the respondents' lifestyle, there is a tendency of those students who smoke $(36,5 \%)$ to consume eggs every day (Pearson's chi-square test significant with $\mathrm{p}<0.05$ ) (Table 7). The following table, instead, shows the tendency of those who do not drink alcohol to consume eggs more frequently (Table 8). Moreover, we also analyzed the relationship between egg consumption and the sport activities practised by students. The results show that those who occasionally practise sport activities (once or twice a week), are more inclined to consume eggs (Table 9). We can also highlight a higher daily egg consumption among the students coming from large households (Table 10). Finally, the students who mostly consume eggs are aged on average between 21 and 22 (Table 11).

Table 3. Weekly consumption of eggs

\begin{tabular}{lrl}
\hline Everyday & 8 & $2,70 \%$ \\
$3-5$ times a week & 62 & $20,95 \%$ \\
$1-2$ times a week & 191 & $64,53 \%$ \\
Never & 35 & $11,82 \%$ \\
\hline
\end{tabular}

Table 4. Consumption mode

\begin{tabular}{lr} 
Individual consumption & $46,50 \%$ \\
\hline
\end{tabular}

Consumption with other ingredients $\quad 53,50 \%$

Table 5. Availability spending

\begin{tabular}{ll} 
Up to 30 cents & $21 \%$ \\
Up to 50 cents & $32 \%$ \\
I do not know & $47 \%$ \\
\hline
\end{tabular}

Table 6. Consumption mode for gender Man

Weekly consumption of eggs

\begin{tabular}{lrl}
\hline Everyday & 45 & $42,00 \%$ \\
$3-5$ times a week & 35 & $32,00 \%$ \\
$1-2$ times a week & 27 & $25,00 \%$ \\
Never & 1 & $1,00 \%$ \\
Total & 108 & $100,00 \%$ \\
Do not respond & 9 & \\
Woman & & \\
Weekly consumption of eggs & & \\
Everyday & 89 & $44,10 \%$ \\
$3-5$ times a week & 51 & $28,30 \%$ \\
$1-2$ times a week & 50 & $25,30 \%$ \\
Never & 6 & $2,30 \%$ \\
Total & 196 & $100,00 \%$ \\
Do not respond & 9 & \\
\hline
\end{tabular}

Table 7. How many times a week do you eat eggs? Do you smoke?

\begin{tabular}{|c|c|c|c|c|}
\hline & \multicolumn{4}{|c|}{ Do you smoke? } \\
\hline & Yes & No & Ex & Total \\
\hline \multirow[t]{2}{*}{ Everyday } & 35 & 92 & 7 & 134 \\
\hline & $36,50 \%$ & $3,20 \%$ & $0,00 \%$ & $39,70 \%$ \\
\hline \multirow{2}{*}{$3-5$ times } & 23 & 35 & 4 & 62 \\
\hline & $24,50 \%$ & $18,50 \%$ & $30,80 \%$ & $20,90 \%$ \\
\hline \multirow[t]{2}{*}{ 1-2 times } & 58 & 126 & 7 & 191 \\
\hline & $61,70 \%$ & $66,70 \%$ & $53,80 \%$ & $64,50 \%$ \\
\hline \multirow[t]{2}{*}{ Never } & 11 & 22 & 2 & 35 \\
\hline & $11,70 \%$ & $11,60 \%$ & $15,40 \%$ & $11,80 \%$ \\
\hline \multirow[t]{2}{*}{ Total } & 94 & 189 & 13 & 296 \\
\hline & $100,00 \%$ & $100,00 \%$ & $100,00 \%$ & $100,00 \%$ \\
\hline
\end{tabular}


Carlo Giannetto et al. / American Journal of Applied Sciences 2016, 13 (6): 697.707 DOI: 10.3844/ajassp.2016.697.707

Table 8. How many times a week do you eat eggs? What about alcohol consumption?

\begin{tabular}{|c|c|c|c|c|}
\hline & \multicolumn{4}{|c|}{ Alcohol consumption? } \\
\hline & Yes & No & Rarely & Total \\
\hline \multirow[t]{2}{*}{ Everyday } & 0 & 6 & 2 & 8 \\
\hline & $0,00 \%$ & $4,40 \%$ & $1,70 \%$ & $2,70 \%$ \\
\hline \multirow[t]{2}{*}{ 3-5 times } & 11 & 23 & 28 & 62 \\
\hline & $27,50 \%$ & $17,00 \%$ & $23,10 \%$ & $20,90 \%$ \\
\hline \multirow[t]{2}{*}{ 1-2 times } & 26 & 90 & 75 & 191 \\
\hline & $65,00 \%$ & $66,70 \%$ & $62,00 \%$ & $64,50 \%$ \\
\hline \multirow[t]{2}{*}{ Never } & 3 & 16 & 16 & 35 \\
\hline & $7,50 \%$ & $11,90 \%$ & $13,20 \%$ & $11,80 \%$ \\
\hline \multirow[t]{2}{*}{ Total } & 40 & 135 & 121 & 296 \\
\hline & $100,00 \%$ & $100,00 \%$ & $100,00 \%$ & $100,00 \%$ \\
\hline
\end{tabular}

Table 9. How many times a week do you eat eggs? How many times a week do you practise sport activities?

\begin{tabular}{|c|c|c|c|c|c|}
\hline & Everyday & 3-5 times & 1-2 times & Never & Totale \\
\hline \multirow[t]{2}{*}{ Everyday } & 2 & 2 & 2 & 2 & 8 \\
\hline & $10,50 \%$ & $2,30 \%$ & $1,70 \%$ & $2,80 \%$ & $2,70 \%$ \\
\hline \multirow[t]{2}{*}{$3-5$ times } & 8 & 19 & 18 & 17 & 62 \\
\hline & $42,10 \%$ & $21,60 \%$ & $15,40 \%$ & $23,60 \%$ & $20,90 \%$ \\
\hline \multirow[t]{2}{*}{ 1-2 times } & 9 & 56 & 83 & 43 & 191 \\
\hline & $47,40 \%$ & $63,60 \%$ & $70,90 \%$ & $59,70 \%$ & $64,50 \%$ \\
\hline \multirow[t]{2}{*}{ Never } & 0 & 11 & 14 & 10 & 35 \\
\hline & $0,00 \%$ & $12,50 \%$ & $12,00 \%$ & $13,90 \%$ & $11,80 \%$ \\
\hline \multirow[t]{2}{*}{ Total } & 19 & 88 & 117 & 72 & 296 \\
\hline & $100,00 \%$ & $100,00 \%$ & $100,00 \%$ & $100,00 \%$ & $100,00 \%$ \\
\hline
\end{tabular}

Table 10. How many times a week do you eat eggs? How many people are there in your family?

\begin{tabular}{lllll}
\hline & $<=3$ comp. & 4 comp. & $>=5$ comp. & Total \\
\hline Everyday & 1 & 2 & 5 & 8 \\
& $1,40 \%$ & $1,50 \%$ & $6,60 \%$ & $2,80 \%$ \\
$3-5$ times & 17 & 29 & 12 & 58 \\
& $23,90 \%$ & $21,30 \%$ & $15,80 \%$ & $20,50 \%$ \\
$1-2$ times & 46 & 91 & 46 & 183 \\
& $64,80 \%$ & $66,90 \%$ & $13,50 \%$ & $64,70 \%$ \\
Never & 7 & 14 & $17,10 \%$ & 34 \\
& $9,90 \%$ & $10,30 \%$ & 76 & $12,00 \%$ \\
Total & 71 & 136 & $100,00 \%$ & 283 \\
& $100,00 \%$ & $100,00 \%$ & & $100,00 \%$ \\
\hline
\end{tabular}

Table 11. How many times a week eggs consumption? Which age group do you belong to?

\begin{tabular}{lllll}
\hline & $<=21$ age & $22-24$ age & $>=25$ age & Total \\
\hline Everyday & 3 & 3 & 2 & 8 \\
& $3,10 \%$ & $2,70 \%$ & $2,40 \%$ & $2,80 \%$ \\
$3-5$ times & 22 & 23 & 15 & 60 \\
& $22,90 \%$ & $20,70 \%$ & $18,30 \%$ & $20,80 \%$ \\
$1-2$ times & 62 & 69 & 56 & 187 \\
& $64,60 \%$ & $62,20 \%$ & $68,30 \%$ & $64,70 \%$ \\
Never & 9 & 16 & 9 & 34 \\
& $9,40 \%$ & $14,40 \%$ & $11,00 \%$ & $11,80 \%$ \\
Total & 96 & 111 & 82 & 289 \\
& $100,00 \%$ & $100,00 \%$ & $100,00 \%$ & $100,00 \%$ \\
\hline
\end{tabular}

Analysis of the University Student's Egg Consumption: Economic Interpretation of the Results

The data collection technique that was used consisted of the administration of a distributed anonymous questionnaire by directly interviewing a sample of university students with the face to face method and by using a questionnaire form which was prepared ad hoc. It has provided a good estimate on the average consumption of eggs by the university population of Messina, offering the advantage of flexibility in data 
management. This research demonstrated that the employed model was appropriate to characterize the economic analysis realized. The estimate of food consumption is an indispensable means for assessing the exposure of consumers to the dangers involved in food intake. The data collected from this survey can integrate information, so far insufficient, on the consumption of eggs in shell by the student population of Messina. The survey revealed interesting differences in consumption patterns, due to different lifestyle (sports, smoking and alcohol consumption), to the area of residence, to the age group, to the number of family members. The survey has highlighted two economic implications which satisfactorily identify the dynamics of egg consumption. The conducted analysis shows that the domestic purchases of eggs are not affected by changes in the prices of possible substitutes (Fig. 2).

In agreement with the theory of consumer, the pattern of purchases is inversely related to their price (Fig. 3).

The economic theory that studies the elasticity of the demanded quantity of a good by altering another quantity (price, income and price of other goods), states that the degree of responsiveness of demand with respect to price is also dependent on the availability or otherwise of substitute products. Therefore, since eggs have no viable substitutes, they have a more inelastic demand that reacts less to the market price fluctuations. Despite the recent period of economic crisis that has affected the company and despite the reduction in income, the share of food consumption of eggs has not diminished (as provided by the law of Engel) (Fig. 4).

This phenomenon is also determined by the fact that students are more aware of the health benefits that agricultural products can provide. Certainly the breadth and diversity of egg supply has enabled consumers to seize savings opportunities more easily. The loss of purchasing power that has particularly affected young people, has created more rational consumption policies leading to a reduction in waste, especially in the food sector. This phenomenon has also involved the consumption style of the students of Messina (Fig. 5). The Fig. 5 shows an estimate of the amount of uneaten food that goes to waste. The $35 \%$ of consumers say that sheds little food, the $45 \%$ of respondents said they dispose of very little uneaten food. The $16 \%$ of respondents are not wasting food while only $4 \%$ say they produce many food waste from food still not used.

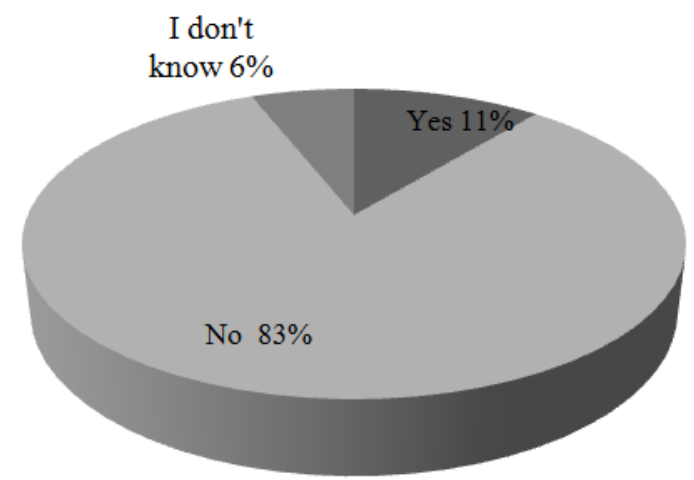

Fig. 2. The purchase of eggs is influenced by changes in the prices of possible substitutes?

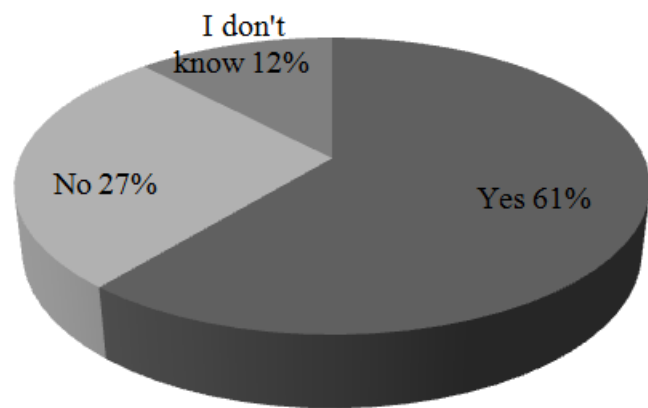

Fig. 3. The purchases of eggs depends on their price?

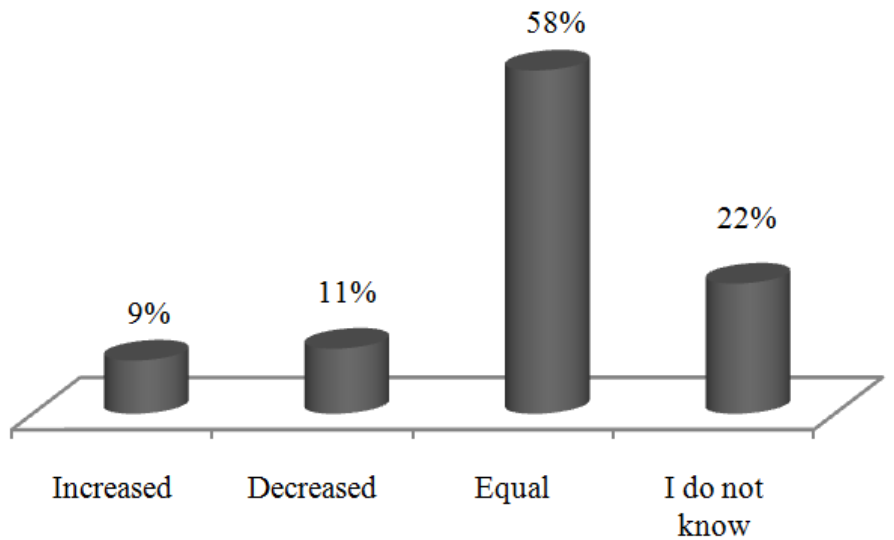

Fig. 4. Amount of uneaten food in the waste 


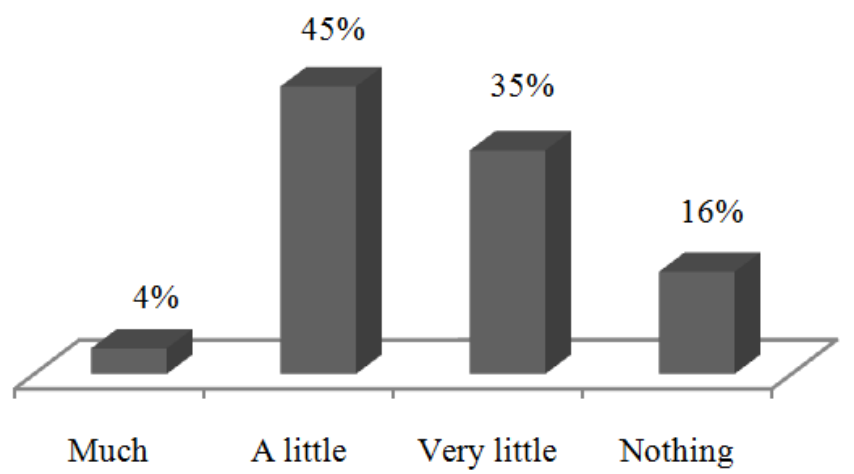

Fig. 5. Amount of uneaten food in the waste

With reference to the structure of the Italian meal the consumption of bread and cereals (pasta, rice, biscuits, ready meals), meat (including sausages), milk, cheese and eggs prevails. The health consciousness has created in twenty years an increase monthly of per capita spending of 3 euro for the consumption of fruit and 5 euro for that of vegetables. The carried out study leads, therefore, to propose the implementation of a nutritional education and information system that will foster the dissemination of healthy eating patterns able to correct the eating habits of young people in order to prevent any diseases in adulthood related to incorrect food styles. The main application of the results obtained in this study consists on one hand to provide useful information for the study of consumer behavior and his willingness to pay a price surplus for a quality product that gives a greater guarantee of food safety and on the other hand, a possible reduction of the costs related to the national health system and generated by incorrect feeding patterns.

\section{Logistic Regression Model: Theoretical Foundations}

To verify the possible dependence of the dichotomous variable "Customer loyalty" by some potential predictors, we decided to estimate a Generalized Linear Model, in particular the Binary Logistic Regression Model. This kind of model (Kleinbaum and Klein, 2010) formalizes the dependence between a dichotomous outcome variable and one or more independent covariates. It estimates probabilities using a logistic function, i.e., the cumulative logistic distribution. It calculates the probability that a feature is present (e.g., probability of "success" ") given the values of explanatory variables, that is a single categorical variable:

$$
\pi=\operatorname{Pr}(Y=1 \mid X=x)
$$

Let $\mathrm{Y}$ be a binary outcome variable:
- $Y_{i}=1$ if the trait is present in observation (unit, person, etc...) $i$

- $Y_{i}=0$ if the trait is not present in observation $i$

- $X=\left(X_{1}, X_{2}, \ldots, X_{k}\right)$ be a set of explanatory variables; they can be discrete, continuous or a combination. $x i$ is the observed value of the explanatory variables for observation $i$

The aim of logistic regression is to find the best fitting model to explain the relation between the dichotomous feature of interest (response or outcome variable) and some independent explanatory variables (predictors). In logistic regression model the coefficients and its standard errors predict a logit transformation for the probability of presence of the interest feature.

Focusing on a single variable $\mathrm{X}$, the model is expressed by:

$$
\pi_{i}=\operatorname{Pr}\left(Y_{i}=1 \mid X_{i}=x_{i}\right)=\frac{\exp \left(\beta_{0}+\beta_{1} x_{i}\right)}{1+\exp \left(\beta_{0}+\beta_{1} x_{i}\right)}
$$

Or:

$\operatorname{logit}\left(\pi_{i}\right)=\log \left(\frac{\pi_{i}}{1-\pi_{i}}\right)=\beta_{0}+\beta_{1} x_{i}=\beta_{0}+\beta_{1} x_{i 1}+\ldots+\beta_{k} x_{i k}$

In this way, the log odds of the outcome is a linear combination of the predictive variables. Binary Logistic Regression is based on certain assumptions:

- The data $Y_{1}, Y_{2}, \ldots, Y_{n}$ are independent and identically distributed

- Distribution of $Y i$ is $\operatorname{Bin}\left(n_{i}, \pi_{i}\right)$, i.e., binary logistic regression model assumes binomial distribution of the outcome variable

- It does not assume a linear relationship between the dependent variable and the independent covariates, but it assume linear relationship between the logit of the response and the explanatory variables: 


$$
\log i t(\pi)=\beta_{0}+\beta_{1} X
$$

- The homogeneity of variance does not need to be satisfied

- Errors need to be independent but not normally distributed

- It uses Maximum Likelihood Estimation (MLE) rather than Ordinary Least Squares (OLS) in order to estimate the parameters
- Goodness-of-fit measures are based on sufficiently large samples

For overall goodness-of-fit statistics of logistic regression model (NorušisMarija, 2009), we considered some measures as $-2 \log$ Likelihood value, the Hosmer-Lemeshow test (Hosmer and Lemeshow, 2000); Cox and Snell R-Square and Nagelkerke RSquare.

Table 12. Results of the univariate logistic regression models for eggs consumption

\begin{tabular}{llllll}
\hline Predictors & $\mathrm{B}$ & $\mathrm{S} . \mathrm{E}$. & Sig. & Exp(B) & $95 \%$ C.I. \\
\hline Age & $-0,003$ & 0,051 & 0,960 & 0,997 & $0,903-1,101$ \\
Constant & 2,110 & 1,198 & 0,078 & 8,245 & - \\
Sex & $-0,356$ & 0,365 & 0,329 & 0,701 & $0,343-1,432$ \\
Constant & 2.180 & 0,236 & 0,000 & 8,850 & - \\
Number of family members & -0.351 & 0,205 & 0,087 & 0,704 & $0,471-1,052$ \\
Constant & 3.456 & 0,885 & 0,000 & 31,698 & - \\
Father educational level & 0,102 & 0,268 & 0,702 & 1,108 & $0,656-1,872$ \\
Constant & 1,789 & 0,545 & 0,001 & 5,984 & - \\
Mother educational level & $-0,170$ & 0,272 & 0,531 & 0,844 & $0,495-1,437$ \\
Constant & 2,372 & 0,571 & 0,000 & 10,718 & - \\
Smoke & 0,008 & 0,387 & 0,984 & 1,008 & $0,472-2,152$ \\
Constant & 2,037 & 0,217 & 0,000 & 7,667 & - \\
Alcool consumption & 0,001 & 0,361 & 0,999 & 1,000 & $0,493-2,027$ \\
Constant & 2,040 & 0,266 & 0,000 & 7,687 & - \\
Sport practice & 0,253 & 0,401 & 0,528 & 1,287 & $0,587-2,823$ \\
Constant & 1,856 & 0,340 & 0,000 & 6,400 & - \\
Food style & 2,560 & 0,577 & 0,000 & 12,938 & $4,179-40,061$ \\
Constant & $-0,288$ & 0,540 & 0,594 & 0,750 & - \\
Read of the product label & 1,417 & 0,585 & 0,015 & 4,126 & $1,310-12,992$ \\
Constant & 2,180 & 0,293 & 0,000 & 8,846 & - \\
Knowledge of rearing hens type & $-0,041$ & 0,595 & 0,946 & 0,960 & $0,299-3,079$ \\
Constant & 2,818 & 0,515 & 0,000 & 16,750 & - \\
Spending availability for organic egg & 0,803 & 0,379 & 0,034 & 2,232 & $1,063-4,684$ \\
Constant & 2,308 & 0,300 & 0,000 & 10,052 & - \\
\hline
\end{tabular}

Table 13. Results of the multivariate logistic regression model for eggs consumption

\begin{tabular}{llllll}
\hline Predictors & B & S.E. & Sig. & Exp(B) & 95\% C.I. \\
\hline Constant & 3,861 & 3,285 & 0,240 & 47,510 & - \\
Age & $-0,133$ & 0,095 & 0,158 & 0,875 & $0,727-1,053$ \\
Sexo & $-0,558$ & 0,751 & 0,458 & 0,572 & $0,131-2,495$ \\
Number of family members & $-0,384$ & 0,373 & 0,303 & 0,681 & $0,328-1,414$ \\
Father educational level & 0,839 & 0,619 & 0,175 & 2,315 & $0,688-7,784$ \\
Mother educational level & $-0,999$ & 0,608 & 0,100 & 0,368 & $0,112-1,211$ \\
Smoke & $-0,378$ & 0,692 & 0,585 & 0,685 & $0,176-2,661$ \\
Alcool consumption & 0,439 & 0,678 & 0,517 & 1,551 & $0,411-5,859$ \\
Sport practice & 1,211 & 0,739 & 0,101 & 3,356 & $0,788-14,284$ \\
Food style & 3,428 & 0,969 & 0,000 & 30,803 & $4,606-205,98$ \\
Read of the product label & 1,614 & 0,752 & 0,032 & 5,022 & $1,150-21,923$ \\
Knowledge of rearing hens type & $-1,370$ & 0,839 & 0,103 & 0,254 & $0,049-1,316$ \\
Spending availability for organic egg & 0,906 & 0,475 & 0,056 & 2,474 & $0,975-6,274$ \\
\hline
\end{tabular}

Table 14. Goodness of fit for multivariate model

\begin{tabular}{lrr}
\hline Statistics & Value & p-value \\
\hline -2 Log-Likelihood & 88.137 & \\
Cox and Snell R-Square & 0.171 & \\
Nagelkerke R-Square & 0.281 & 0.655 \\
Hosmer-Lemeshow Test & 5.928 & \\
\hline
\end{tabular}


For the parameters estimation, we used the Maximum Likelihood Estimator (MLE): In particular the ML estimates are obtained by using iterative algorithms such as Newton-Raphson (NR) or Iteratively Re-Weighted Least Squares (IRWLS) (Agresti, 2013).

\section{Results of the "Logistic Regression Model" Estimation}

In order to assess the dependence of the dichotomous variable "Eggs consumption" by a set of potentially predictive explanatory variables, the logistic regression model was estimated. At first we estimated univariate models for each potentially predictive variables (Table 12) and, then, multivariate model (Table 13). For every model we reported the B coefficient with the Standard Error (S.E.), the p-value, the exponential of B value with $95 \%$ Confidence Interval (C.I.). Based on the results obtained from the univariate regression models estimation (Table 12), we can conclude that the only statistically significant variables are the food style of the consumer, the read of the product label and the spending availability for organic egg. By the results shown in Table 13 we can notice that the only two variables, that are statistically significant in multivariate approach, are the food style and the read of the product label. In Table 14 we showed the value of -2 Log-Likelihood, Cox and Snell R-Square and Nagelkerke R-Square to assess the goodness of fit, within a Binary Logistic Regression Model; these three statistics guarantee the appropriate degree of model fit to our data, since the value is quite small. Moreover, we also reported the Hosmer and Lemeshow test that provides measures about the adequacy of the model to observed data; it does not result statistically significant, ensuring that the theoretical values obtained from the model estimation do not significantly differ from the empirical values.

\section{Conclusion}

The investigation has highlighted that only $64,53 \%$ of the interviewed young people declare a consumption of about two eggs a week, a slightly lower data compared to the national one, which is equal to around three eggs a week. However, this data is in line with the national ones, which show that Italy, compared to the other EU countries, makes very limited use of eggs, exceeding in meat consumption, instead. In essence, most of the sample declares to consume eggs on a weekly basis. Therefore, the carried out study leads us to propose the implementation of a food education and information system likely to encourage the spread of healthy food models, which are aimed at correcting young people's eating habits (Gracia et al., 2014). In conclusion, the results produced by this survey can certainly be used as an important starting point for future research. Indeed, it is a pilot survey on an adequate number of interviewed people in which information appears to be of particular importance. In fact, $46 \%$ of the interviewed youngsters declare to be not sufficiently informed on proper eating styles and on the indications given on the label. Lastly, even the percentage of those who are willing to spend more for purchasing biological eggs because they consider them to be of better quality and attach a greater food security to them, is significant.

\section{Author's Contributions}

The work is the result of a full collaboration of the authors.

Maurizio Lanfranchi: He participated coordination and setting of the study, designed the research plan, interpretations of data and contributed to the writing and reviewing the manuscript.

Carlo Giannetto: Involved in data investigation and drafting the manuscript.

Agata Zirilli and Angela Alibrandi: Contributed to the writing related statistical analysis and to the interpretations of data.

\section{Ethics}

This article is original and has not published elsewhere.

\section{References}

Agresti, A., 2013. Categorical Data Analysis. 3rd Edn., John Wiley and Sons, Hoboken, ISBN-10: 1118710940, pp: 744.

Andersen, L.M., 2011. Animal welfare and eggs-Cheap talk or money on the counter? J. Agric. Econ., 62: 565-584. DOI: 10.1111/j.1477-9552.2011.00310.x

Caracciolo, F., G. Di Vita, M. Lanfranchi and M. D'Amico, 2015. Determinants of sicilian wine consumption: Evidence from a binary response model. Am. J. Applied Sci., 12: 794-801.

DOI: 10.3844/ajassp.2015.794.801

Cembalo, L., A. Lombardi, S. Pascucci, D. Dentoni and G. Migliore et al., 2015. "Rationally local": Consumer participation in alternative food chains. Agribusiness, 31: 330-352. DOI: 10.1002/agr.21419

Colas, B., F. Sauvageot, J.P. Hmcoat and B. Sauveur, 1979. Ann. Zootech., 28: 297-297.

Katz, D.L., M.A. Evans, H. Nawaz, V.Y. Njike and W. Chan et al., 2005. Egg consumption and endothelial function: A randomized controlled crossover trial. Int. J. Cardiol., 99: 65-70. DOI: 10.1016/j.ijcard.2003.11.028

EUFIC, 2010. RassegneThe European Food Information Council 01/2012 European Food Safety Authority. The EU Menu. 
Fearne, A. and D. Lavelle, 2011. Segmenting the UK egg market: Results of a survey of consumer attitudes and perceptions. British Food J., 98: 7-12. DOI: $10.1108 / 00070709610111269$

Gracia, A., J. Barreiro-Hurlé and B. López-Galán, 2014. Are local and organic claims complements or substitutes? A consumer preferences study for eggs. J. Agric. Econ., 65: 49-67. DOI: $10.1111 / 1477-9552.12036$

Hayat, Z., G. Cherian, T.N. Pasha, F.M. Khattak and M.A. Jabbar, 2010. Sensory evaluation and consumer acceptance of eggs from hens fed flax seed and 2 different antioxidants. Poultry Sci., 89: 2293-298. DOI: 10.3382/ps.2009-00575

Heuer, T., C. Krems, K. Moon, C. Brombach and I. Hoffmann, 2015. Food consumption of adults in Germany: Results of the German National Nutrition Survey II based on diet history interviews. British J. Nutrit., 113: 1603-1614.

DOI: $10.1017 / \mathrm{S} 0007114515000744$

Hosmer, D. and S. Lemeshow, 2000. Applied Logistic Regression. 2nd Edn., John Wiley and Sons, Inc., New York, ISBN-10: 0471356328, pp: 373.

Kleinbaum, D.G. and M. Klein, 2010. Logistic Regression: A Self-Learning Text. 2nd Edn., Springer, New York, ISBN-10: 1441929843, pp: 513.

Kosa, K.M., S.C. Cates, S. Bradley, S. Godwin and D. Chambers, 2015. Consumer shell egg consumption and handling practices: Results from a national survey. J. Food Protect., 78: 1312-1319. DOI: 10.4315/0362-028X.JFP-14-574

Lanfranchi, M., C. Giannetto and A. De Pascale, 2014a. The role of nature-based tourism in generating multiplying effects for socio economic development of rural areas. Quality-Access Success, 15: 96-100.

Lanfranchi, M., C. Giannetto and A. De Pascale, 2014b. Analysis and models for the reduction of food waste in organized large-scale retail distribution in eastern sicily. Am. J. Applied Sci., 11: 1860-1874.

DOI: 10.3844 /ajassp.2014.1860.1874

Lanfranchi, M., C. Giannetto, A. Alibrandi and A. Zirilli, 2015. Analysis of the propensity to fruit consumption among young people through the cumulative proportional odds model. Am. J. Applied Sci., 12: 542-548.

DOI: 10.3844 /ajassp.2015.542.548

Lanfranchi, M., C. Giannetto, M. D'Amico and G. Di Vita, 2014c. Analysis of demand determinants of fish products in Messina: An economic survey on the fish consumption. Quality-Access Success, 15: 106-108.

Djoussé, L. and J.M. Gaziano, 2008. Egg consumption and cardiovascular disease and mortality the physicians' health study. Am. J. Clin. Nutr., 87: 964-969.

Maga, J.A., 1982. Egg and egg product flavor. J. Agric. Food Chem., 30: 9-14. DOI: 10.1021/jf00109a002
Memon, A., A.S. Memon, A.H. Soomro, N. Rajput and I.H. Leghari et al., 2009. Study on consumption of chicken eggs in Hyderabad district. Pak. J. Nutr., 8: 1480-1485. DOI: 10.3923/pjn.2009.1480.1485

Mesías, F.J., F. Martínez-Carrasco, J.M. Martínez and P. Gaspar, 2011. Functional and organic eggs as an alternative to conventional production: A conjoint analysis of consumers' preferences. J. Sci. Food Agric., 91: 532-538. DOI: 10.1002/jsfa.4217

Migliore, G., M. Crescimanno, G. Schifani, P. Romeo and A. Galati, 2015a. Quality perception and consumer choice of cactus pear: Results of direct survey in Italy. Acta Hortic., 1067: 275-281. DOI: 10.17660/ActaHortic.2015.1067.38

Migliore, G., M. Di Gesaro, V. Borsellino, A. Asciuto and E. Schimmenti, 2015b. Understanding consumer demand for sustainable beef production in rural communities. Quality-Access Success, 16: 75-79.

Migliore, G., A. Galati, P. Romeo, M. Crescimanno and G. Schifani, 2015c. Quality attributes of cactus pear fruit and their role in consumer choice: The case of Italian consumers. British Food J., 117: 1637-1651. DOI: $10.1108 /$ BFJ-04-2014-0147

NorušisMarija, J., 2009. PASW Statistic 18. Statistical Procedures Companion, Pearson Education.

Oliveira, D.A., P. Benelli and E.R. Amante, 2013. A literature review on adding value to solid residues: Egg shells. J. Cleaner Product., 46: 42-47. DOI: $10.1016 /$ j.jclepro.2012.09.045

Pecorino, B., M. Signorello and G. Trovato, 2016. How sensory attributes affect consumption of functional foods? Evidences from a consumer test in Sicily (Italy). Quality-Access Success, 17: 113-117.

Schimmenti, E., A. Galati, V. Borsellino, C. Ievoli and C. Lupi et al., 2013. Behaviour of consumers of conventional and organic flowers and ornamental plants in Italy. Hortic. Sci., 40: 162-171.

Song, W.O. and J.M. Kerver, 2000. Nutritional contribution of eggs to American diets. J. Am. Coll. Nutr., 19: 556S-562S.

DOI: $10.1080 / 07315724.2000 .10718980$

Sumner, D.A., H. Gow, D. Hayes, W. Matthews and B. Norwood et al., 2011. Economic and market issues on the sustainability of egg production in the United States: Analysis of alternative production systems. Poultry Sci., 90: 241-250.

DOI: $10.3382 /$ ps.2010-00822

Tonsor, G.T., 2011. Consumer inferences of food safety and quality. Eur. Rev. Agric. Econ., 38: 213-235. DOI: $10.1093 /$ erae/jbr011

Tudisca, S., A.M. Di Trapani, E. Donia, F. Sgroi and R. Testa, 2015. The market reorientation of farms: The case of olive growing in the Nebrodi area. J. Food Prod. Market., 21: 179-192. DOI: $10.1080 / 10454446.2013 .843484$ 
Tudisca, S., A.M. Di Trapani, F. Sgroi, R. Testa and G. Giamporcaro, 2014. Role of alternative food networks in Sicilian farms. Int. J. Entrepreneurship Small Bus., 22: 50-63.

DOI: 10.1504/IJESB.2014.062130

Wilkins, J.L., E. Bowdish and J. Sobal, 2000. University student perceptions of seasonal and local foods. J. Nutrit. Educ. Behav., 32: 261-268.

DOI: 10.1016/S0022-3182(00)70574-7
Winkler, J., 2015. High levels of dioxin-like PCBs found in organic-farmed eggs caused by coating materials of asbestos-cement fiber plates: A case study. Environ. Int., 80: 72-78. DOI: 10.1016/j.envint.2015.03.005

Zazpe, I., J.J. Beunza, M. Bes-Rastrollo, J. Warnberg and C. De La Fuente-Arrillaga et al., 2011. Egg consumption and risk of cardiovascular disease in the SUN Project. Eur. J. Clin. Nutrit., 65: 676-682. DOI: $10.1038 /$ ejcn.2011.30 